\title{
Diseño de un software para la enseñanza de Inglés Técnico en Ingeniería: enfoque teórico de su elaboración
}

\author{
Designing educative software for Technical English teaching in \\ Engineering: theoretical approach to its elaboration
}

\begin{abstract}
Ana Finol de Govea
afinol@fing.luz.edu.ve

María Elena Alvarado

melalvarado@fing.luz.edu.ve

Universidad del Zulia, Facultad de Ingeniería.

Maracaibo-Venezuela
\end{abstract}

\section{RESUMEN}

El estudio surge de la necesidad académica de desarrollar destrezas lectoras en lenguaje multimedia y dotar el aula multimedia de Inglés Técnico con materiales digitalizados. La investigación es documental-descriptiva y describe la metodología para diseñar un software para la enseñanza de Inglés Técnico en Ingeniería. La teoría se fundamenta en las características del lenguaje multimedia; principios del diseño instruccional hipermedia; las etapas de elaboración de un software educativo; el hardware utilizado; los programas utilizados en la producción; y la estructura lógica y organización interna, la identificación de vocabulario para ejemplos y ejercicios que permitan la integración y retroalimentación. Las fases metodológicas se centran en la selección de los contenidos programáticos y los ejercicios de retroalimentación; y los tópicos de los textos acordes con la madurez de los estudiantes y la interdisciplinaridad académica, todo basado en criterios para la elaboración de diseños instruccionales multimedia. Los resultados determinaron la metodo- 
logía para la elaboración de un software en la enseñanza de Inglés Técnico, los cuales permiten el acceso al contenido programático en formato multimedia donde se consideran aspectos del lenguaje total como: texto, sonido, hipertexto, animación e imágenes que actualizan el proceso de enseñanza del Inglés Técnico en ambientes digitales.

Palabras clave: Software educativo, enseñanza de Inglés Técnico, destrezas lectoras, lenguaje multimedia.

\begin{abstract}
The study comes from the academic need to develop reading skills in multimedia language and to provide the multimedia Technical English classroom with digital materials. It is a documental-descriptive research and describes the methodology for designing educative software for Technical English teaching in Engineering. The theory is based on multimedia language features, such as: principles of hypermedia instructional design; the programs used in software production; the logical structure and internal organization; and the vocabulary identification for examples and exercises that allows integration and feedback. Methodological phases focus on the selection of the programmatic content and feedback exercises; topics selection of texts are chosen according to the students' maturity and academic disciplines, all this based on criteria for the elaboration of multimedia instructional designs. The results determined the software development methodology for technical English teaching which allows access to the program content in multimedia format. In this software design most of the total language aspects are considered, such as: text, sound, hypertext, animation, and images that updated the Technical English teaching process in digital environments.
\end{abstract}

Key words: Educational software, Technical English teaching, reading skills, multimedia language.

\title{
PLANTEAMIENTO DEL PROBLEMA
}

Actualmente la enseñanza universitaria se encuentra en la necesidad de asistirse por las tecnologías de la información y la comunicación (TIC) con el fin de formar profesionales competentes y altamente capacitados (Clemente et al., 2000). Los profesionales universitarios que se están formando hoy día necesitan estar inmersos y ser competentes en el manejo de información di- 
gitalizada debido a las exigencias del mundo actual (Cabero, 2007). Los procesos de comunicación e información realizados en las diferentes actividades personales, académicas y profesionales se deben regir por las competencias del mundo de la informática (Crook, 1998), y el manejo de información en inglés relacionada con la disciplina de estudio (Macías, 2015). Este requerimiento se logra básicamente con el uso de software educativos ejercitadores (Marquès, 2003).

En la enseñanza de Inglés Técnico en el Aula Multimedia de la Facultad de Ingeniería de la Universidad del Zulia se ha introducido el software educativo para la ejercitación en textos multimedia de las estructuras morfológicas, sintácticas, gramaticales y semánticas del inglés en textos científicos de ingeniería (Batista \& Finol, 2005, Salinas, 1996), las cuales están presentes en los contenidos de los programas de estudio vigentes (Programas de estudios de Inglés Técnico, 2008). De este modo se preparan y capacitan a los estudiantes en el desarrollo de destrezas de comprensión lectora en lenguaje multimedia.

También es conocido el hecho de que las empresas requieren profesionales que satisfagan tanto sus demandas profesionales como el dominio y manejo de información digital en inglés (Clemente et al., 2000, Cáceres, 2016). El software educativo facilita esta demanda de forma amena e interactiva (Macías, 2015), por medio de la aplicación de técnicas y destrezas efectivas de lectura, la extracción de información de textos científicos multimedia en inglés (González, Marcovecchio, Margarit \& Ureta, 2008).

El estudio surge de dos aspectos principales: primero de la necesidad académica de desarrollar destrezas lectoras en lenguaje multimedia (Gavarri, 2016, Prado, 2005); y luego para dotar el aula multimedia de Inglés Técnico de la Facultad de Ingeniería de la Universidad del Zulia con materiales digitalizados. Estos aspectos se fundamentan en las siguientes razones:

1. La relevancia actual del idioma inglés.

2. El cambio en el concepto tradicional de la educación debido a la introducción de las nuevas tecnologías de la información y la comunicación.

3. Los cambios en el proceso de enseñanza aprendizaje del Inglés Técnico $y$,

4. Los nuevos requerimientos laborales para los egresados de ingeniería. 
Analicemos brevemente cada uno de estos aspectos.

\section{Relevancia actual del idioma inglés}

Actualmente los avances y descubrimientos producidos en la ciencia y la tecnología relacionados con la Ingeniería se incluyen mayoritariamente, y básicamente en idioma inglés en las publicaciones academico-cientificas. Por esto no dominar el inglés, significa para un estudiante de ingeniería, quedarse rezagado en su desempeño académico y profesional (Wankat y Oreovicz, 1993).

En la educación superior venezolana la presencia del idioma inglés es notoria. Por esta razón, la asignatura Inglés está incluida en casi todas las carreras que se ofrecen tanto en pregrado como en postgrado. La Facultad de Ingeniería de LUZ tiene incluido en sus programas de estudio la asignatura Inglés Técnico, pues se está consciente de la necesidad que tienen los ingenieros de ser capaces de leer textos sobre su especialidad escritos en inglés (Programas de estudios de Inglés Técnico. Facultad de Ingeniería de la Universidad del Zulia, 2008).

\section{El cambio en el concepto tradicional de la educación debido a la intro- ducción de las recursos instruccionales digitalizados}

En esta Era Digital la forma de presentar la información ha cambiado radicalmente, pasando de forma física a forma digital, electrónica o virtual, designándose entonces como Era Digital, Era Electrónica o Virtual (Romero, 2007, Rodríguez \& Planchuelo, 2004). En los estudios de Ingeniería gran parte de la información de consulta proviene de fuentes digitalizadas o virtuales, y la mayoría está escrita en inglés (Batista \& Finol, 2005), es entonces, competencia de esta asignatura proporcionar al alumno un conjunto de estrategias y destrezas de comprensión lectoras que le permitan leer textos multimedia y manejar adecuadamente la información allí presente con fines prácticos (Gavarri, 2016, Vaughan, 2005). El software educativo diseñado con este propósito satisface esta exigencia pedagógica. Esto surge del hecho de que es necesario y es una demanda institucional y de política educativa nacional el diseñar herramientas instruccionales acordes con las tecnologías de la información y la comunicación para la enseñanza de las diferentes asignaturas en la Universidad del Zulia (Consejo Universitario de LUZ, 2007 Consejo Universitario de LUZ, 2006). 


\section{Los cambios en el proceso de enseñanza aprendizaje de Inglés Técnico}

De los textos multimedia se puede obtener una gran cantidad de información actualizada en documentos, textos y tópicos escritos en inglés relacionados con la ingeniería (Prado, 2005, Sánchez, 1999, Salinas, 1996). Esta visión global, multidisciplinar e interdisciplinar en la interpretación de textos multimedia presentes en el software educativo se logra debido a las conexiones o links que caracterizan los textos multimedia (Murcia, Arias, \& Osorio, 2016, González, Marcovecchio, Margarit \& Ureta, 2008). Con relación al perfil profesional del ingeniero, el manejo del idioma inglés en medios digitalizados le permite manejar e interpretar adecuadamente aspectos como: la vigencia de los métodos, la utilización óptima de equipos e instalaciones, el diseño de sistemas, planes y procedimientos en el plano gerencial y operacional en esta era de la globalización, multidisciplinaridad e interdisciplinaridad (Consejo Universitario de LUZ, 2007, Vicerrectorado Académico de LUZ, 2008).

\section{Los nuevos requerimientos laborales para los egresados de ingeniería}

Debido a la relevancia actual del manejo adecuado de la información obtenida a través de las nuevas tecnologías de la información y la comunicación, las empresas demandan, cada vez con mayor urgencia, profesionales que aprecien y sepan utilizar estas herramientas (Rodríguez \& Planchuelo, 2004, Clemente et al., 2000). Entre las principales competencias que se demandan al ingeniero están: la comunicación, la capacidad de trabajo en equipo y el conocimiento de idiomas y de informática (Navarro, Iglesias, \& Torres, 2006). El desarrollo de estas competencias se logra significativa y adecuadamente mediante el uso de recursos instruccionales multimedia como el software educativo (Barajas, 2003).

\section{OBJETIVO DE LA INVESTIGACIÓN}

En razón de lo argumentado, esta investigación tiene como objetivo describir el diseño de un software educativo para la enseñanza de la asignatura Inglés Técnico en la Facultad de Ingeniería de la Universidad del Zulia. Este objetivo se centra en el análisis de los argumentos expuestos anteriormente, que pueden ser englobados en los siguentes aspectos: a) las actuales tendencias educativas de inglés técnico en ingeniería; b) los requerimientos institucionales universitarios, y c) los lineamientos nacionales sobre modernización de las políticas educativas. Se analizan estos aspectos que sirven de sustento teórico al objetivo propuesto. 


\section{FUNDAMENTACIÓN TEÓRICA}

Con relación a las demandas de las recientes tendencias educativas en la enseñanza de Inglés Técnico, con este estudio se encauza la adaptación del proceso de enseñanza de la comprensión lectora en Inglés Técnico en ambientes digitales/multimedia.

En cuanto a los requerimientos institucionales de la Facultad de Ingeniería de la Universidad del Zulia, el diseño del software educativo satisface la necesidad de proporcionar recursos didácticos para el aula multimedia de inglés; este medio instruccional, es decir el software educativo, es totalmente cónsono y adaptado con el estudiante, ya que su diseño proviene del análisis del perfil del alumno, su madurez académica, los temas y tópicos de estudio, y los contenidos programáticos establecidos para la asignatura.

Con respecto a las políticas educativas del país sobre innovación, el estudio obedece a los lineamientos del Estado venezolano establecidos en la Agenda de tecnologías de información y comunicación en educación. Términos de referencia para el desarrollo de contenidos educativos en formato electrónico para la educación básica (2000), donde se promueve y establece el desarrollo de contenidos educativos en formato electrónico para los diferentes niveles y modalidades del sistema educativo venezolano, con la finalidad de adecuar la educación a esta era digital. En esta agenda se considera muy especialmente en la enseñanza de la lengua, la enseñanza de la lectura, ya que ésta promueve el desarrollo de las habilidades verbales e intelectuales, y se considera que la enseñanza de ingles como lengua extranjera entra dentro de esta categoría del desarrollo de los procesos cognitivos del estudiante.

Desde otra perspectiva, el diseño del software educativo tiene dos aspectos de sustentación teórica: a) el diseño instruccional del software y b) el diseño de este en su formato electrónico.

a) Desde el punto de vista pedagógico, el diseño instruccional del software se elaboró de acuerdo con los principales fundamentos de la teoría constructivista y del e-learning. Analicemos ese aspecto.

Para su diseño se consideraron principios del constructivismo combinados con el e-learning. Esta combinación de teóricas pedagógicas permite un entorno digital y o multimedia de enseñanza y aprendizaje (Fernández-Pampillón, 2009). Con esta visión, el software se convierte en un recurso instruccional que integra un conjunto de actividades para la enseñanza-aprendizaje en un medio electrónico, donde se combina la enseñanza 
no presencial (e-learning) o aprendizaje autónomo con la clase presencial (Gavarri, 2016, Murcia et al., 2016, González, Marcovecchio, Margarit \& Ureta, 2008).

En el aprendizaje autónomo el estudiante decide su propio proceso de aprendizaje y durante la clase presencial el docente-facilitador guía estos aprendizajes. De esta manera, esta herramienta instruccional permite no sólo, la interacción con el computador sino la interacción con la información e incluso con los compañeros de clase y con el profesor (Macías, 2015; Salinas, 1996)

Se ha expuesto que este ambiente de aprendizaje digital presenta características propias del aprendizaje electrónico (e-learning) ya que promueve el desarrollo de estrategias de aprendizaje autónomo (Cabero, 2007, Barajas, 2003). Entre las principales actividades autónomas diseñadas en el software están: la telebúsqueda (buscar información específica) o "navegar" en la información presente en el software, y la sincronización de preguntas y repuestas con su feedback o retroalimentación (González, Marcovecchio, Margarit \& Ureta, 2008). Estas actividades se consideran constructivas, ya que el estudiante descubre, procesa y comparte información de acuerdo con sus intereses, motivaciones y necesidades, toma responsabilidad de su propio aprendizaje y negocia en conjunto con su profesor y con sus compañeros el contenido de lo que se aprende y lo que se quiere aprender (Silva \& Ávila, 2000, Bajarlía \& Spiegel, 1997).

Asimismo, estas actividades ofrecen principios de aprendizaje constructivista, ya que: a) promueven y aceptan la iniciativa y la autonomía del estudiante, estos rasgos desarrollan la proactividad y la independencia. b) El ambiente de aprendizaje electrónico ofrece fuentes y datos originales, los cuales pueden ser "físicamente" manipulados e interactuar con ellos. c) Para escoger textos durante la telebúsqueda o navegación el estudiante utiliza terminología cognitiva como: clasificar, analizar, predecir y crear; d) la investigación en el software para la selección de los materiales debe ser discutida en clase; esta actividad permite al estudiante participar activamente en el manejo de los tópicos y los contenidos; e) la telebúsqueda de información permite inferir tanto el nivel de conceptos y conocimientos de los alumnos sobre un tópico determinado como la competencia sobre el idioma; f) durante la navegación, para buscar información sobre un tópico, el estudiante encuentra respuestas específicas para la solución de problemas planteados; y g) durante esta actividad los estudiantes analizan el contenido en términos de vocabularios, estructuras y estrategias de co- 
municación (Cabero, 2007, Bajarlía \& Speigel, 1997). Estas actividades con características cognitivo-constructivistas, retan al estudiante a desplegar las destrezas lectoras y aplicar estrategias de comprensión lectora en inglés en forma autónoma, y verificar la importancia de su aplicación en el procesamiento de información digital (Díaz-Barriga \& Hernández, 2002).

Por otra parte, las preguntas-respuestas con retroalimentación ofrecidas por el software, así como las discusiones grupales realizadas por los alumnos y el profesor en clase sobre un tópico determinado son actividades diseñadas para ser dinámicas y participativas (Marquès, 2000). Estas actividades ofrecen los siguientes principios de aprendizaje constructivista: a) animan al estudiante a descubrir el conocimiento por medio del diálogo; y b) permiten aclarar dudas sobre el contenido del tópico a medida de la discusión (Macías, 2015). Esta discusión-interacción es un importante aspecto en el aprendizaje de una lengua ya que promueve la socialización (Gallego-Badillo, 1998).

De esta forma, en el diseño el software educativo, los aspectos pedagógicos han sido seleccionados para que éste sea un medio adecuado en la transmisión de la información y del conocimiento y promover aspectos inherentes a una enseñanza constructivista como: el procesamiento de la información durante los procesos cognitivos promovidos y desarrollados durante la clase; la interactividad entre alumno-computador-software; y la presencia actividades de aprendizaje entretenidas (García et al., 2016, Murcia et al., 2016). Estos aspectos contribuyen con un aprendizaje significativo y contextualizado (Silvia \& Ávila, 2000; Sánchez, 1999). Es aquí donde se aplica la teoría constructivista en el uso de las tecnologías educativas (software) en la enseñanza de idiomas.

b) La teoría para el diseño del software ejercitador para la enseñanza de Inglés Técnico (formato electrónico) se fundamentó en los siguientes criterios:1) características del lenguaje multimedia; 2) los principios del diseño instruccional multimedia; 3) el hardware utilizado para el diseño; 4) los programas utilizados en la producción; 5) la estructura lógica y la organización interna; y 6) la identificación de vocabulario para satisfacer las necesidades teóricas, ejemplos y ejercicios para mejorar el proceso de aprendizaje y el diseño instruccional que permite la integración y retroalimentación del inglés por medio de ejercicios (Marquès, 2000, 2003, García et al., 2016). 


\section{DISEÑO METODOLÓGICO}

Del marco teórico expuesto se concluye que la investigación es documentaldescriptiva y provee principios básicos para el diseño de un software educativo como recurso instruccional en la enseñanza de Inglés Técnico. A continuación, se analizan los aspectos mencionados anteriormente considerados en el diseño del software.

\section{1) Características del lenguaje multimedia}

Los textos multimedia seleccionados para el software son interactivos y con feedback inmediato. Además, se han elaborado sistemas donde coexisten, el texto, la imagen (fija y en movimiento), la voz, la música, los efectos sonoros y los efectos visuales (García et al., 2016). Todos estos componentes o elementos están relacionados en su diseño de navegación para promover la interpretación textual, gráfica y sonora del idioma simultáneamente. Las características de estos elementos del multimedia son los siguientes (Vaughan, 2005, Salinas, 1996):

- Texto: Las palabras con las cuales se expresa una idea son cuidadosamente escogidas para no crear confusión en el estudiante y que esto altere la interpretación textual. Se utilizan textos para los títulos y los encabezados, para los menús, para la navegación y para el contenido, y se utiliza la información del contenido en textos suficientemente claros y exactos referentes a la especialidad de estudio.

- Sonido: Este elemento despierta el interés en el participante, además es elemento clave en la ejercitación de la pronunciación del vocabulario en los textos suministrados.

- Hipertexto: El sistema de hipertextos es cuidadosamente configurado y vincula en forma organizada, las palabras, oraciones, imágenes, secuencias de video, sonidos y otras ilustraciones relacionadas con el tópico de estudio. El documento hipertextual contiene enlaces a otros documentos y es diseñado para ser explorado libremente, es decir, navegar (leer) a través de él en forma no lineal, rápida e intuitivamente y conseguir así de forma más eficiente una interpretación de las ideas, la información y los mensajes expresados.

- Animación: Es una serie de imágenes que cambian muy ligera y rápidamente, una tras otra, que parecen mezclarse juntas creando la ilusión de movimiento. La animación puede realizarse mediante progra- 
mas especializados como Flash y Director, dando vida, color, textura y movimiento en el espacio a una imagen determinada, por lo general estática. Las animaciones son utilizadas para mantener la atención del participante y captar su atención de manera inmediata en el tema de estudio sin que ocurra el cansancio y la falta de interés. La animación simula la realidad al introducir las principales ideas planteadas en el texto a ser interpretado.

- Imagen: En la enseñanza de ingeniería como disciplina científica, las imágenes son decisivas para la interpretación acertada de la información. Son elementos visuales escogidos de la realidad textual planteada a través de la digitalización de una fotografía, dibujo, diagrama de flujo, gráficos o esquemas, que componen la pantalla multimedia. Los elementos gráficos son dimensionados, animados y coloreados, con patrones gráficos, para colocarse en grande o detrás de otros objetos, o hacerse visibles o invisibles con una orden del usuario en un momento determinado. Las imágenes forman una parte importante de los multimedia a utilizar porque ayudan a desarrollar y aumentar la memoria visual, tan necesaria para la interpretación de textos científicos digitales en inglés.

\section{2) Principios del diseño instruccional multimedia}

En la elaboración del software instruccional multimedia se determinó el grado de interactividad. Se estableció el grado de interacción con el alumno, ya que es en esta fase donde se determina la estructura y secuencia del programa, el control del usuario sobre el mismo y la personalización o estandarización del contenido. Entre las características que inciden directamente en el nivel de interactividad se destacan las siguientes (García et al., 2016, Galvis, 2000).

El formato no secuencial del contenido. Este rasgo permite al programa adaptarse tanto a las necesidades individuales como a la lógica interna del contenido, estructurando el programa en ramificaciones, y presentando suficientes menús del contenido programático para facilitar la interpretación del multimedia o lenguaje total.

La velocidad de las respuestas. Esta mide la importancia de la inmediatez de la respuesta. Si el estudiante quiere o debe saber alguna otra cosa en un programa instruccional el sistema le presenta el gráfico, texto o vídeo inmediatamente. 
Adaptabilidad. Viene dada por el acceso no secuencial al contenido, y viene provista por la interacción de las dos partes: usuario y software. En la respuesta acertada de interpretación textual se considera tanto lo que se dice como el cómo se dice. Esta capacidad de adaptación denota la interactividad del programa.

Proporcionar feedback con segmentos de recuperación. En un software ejercitador este atributo es imprescindible. Con el fin de que el programa sea interactivo se ha incorporado el feedback. Un feedback ordinario del estudiante y un feedback inmediato del programa hacia el receptor como respuesta. Esto ha exigido un diseño cuidadoso del feedback y de los segmentos de recuperación. El feedback está diseñado para aumentar la satisfacción respecto a la instrucción, el interés y facilitar el aprendizaje. En la efectividad del feedback se han considerado rasgos como el ser inmediato y contener información sobre la respuesta.

Opciones. Las opciones seleccionadas en el diseño del software ejercitador proporcionan la posibilidad de control por parte del alumno. Este software interactivo contempla ciertas opciones de control que permiten al usuario: a) Salir y entrar del programa cuando lo desee; b) Seleccionar y/o volver a ver cualquier segmento; c) Ir a segmentos de ayuda cuando lo solicite, y d) Cambiar parámetros del programa al elegir postest o pretest, el grado de dificultad de las preguntas, y otros aspectos.

Comunicación bidireccional. El software interactivo ejercitador tiene un canal que permite la comunicación en dos vías o direcciones: usuario y programa.

\section{3) Hardware utilizado para el diseño}

Entre los equipos de hardware empleados para el desarrollo y producción del software están los siguientes:

- Un (1) computador Intel Pentium IV CPU con velocidad de procesamiento de $3 \mathrm{GHz}, 500 \mathrm{Mb}$ de RAM; Cinco (5) computadores Duo CPU Intel Core2 con velocidad de procesamiento de $2.6 \mathrm{GHz}, 2 \mathrm{~Gb}$ de RAM con monitores LCD de 19"; y Cinco (5) computadores CPU Genuine Intel con velocidad de procesamiento de $1.6 \mathrm{GHz}, 1 \mathrm{~Gb}$ de RAM con monitores LG FLATRON de 19.

- Periféricos para: digitalizar y editar imágenes estáticas y animadas, procesar sonido, para proyectar los programas, etc. 
- Unidades de almacenamiento secundario pendrive, memorias externas y CDs, para realizar respaldos sucesivos en fuentes diferentes.

- Sistema operativo para administrar los recursos: Microsoft Windows XP profesional, versión 2002.

- Programas para retocar la información digitalizada y crear ilustraciones y, para desarrollar las animaciones.

Los equipos para el desarrollo y diseño del software son propiedad del Aula Multimedia de Inglés, del Dpto. Dibujo y Enseñanzas Generales de la Facultad de Ingeniería de la Universidad del Zulia.

\section{4) Programas utilizados en el diseño de software educativo.}

Esta sección detalla el procedimiento informático para el diseño multimedia. Aquí se describen los programas y las herramientas de computación utilizados. En la etapa de definición del trabajo se utilizó el computador, el escáner, licencias, programas y equipos. Los contenidos fueron organizados y digitalizado en el programa Word 2003 de Microsoft Office. Luego se elaboró una primera versión del software educativo basado en herramientas de multiplataforma, desarrollado en lenguaje de HTML y Action Script de Flash; con la capacidad de ser visualizado y leído en cualquier navegador de Internet y ofrecer información estructurada por secciones.

En desarrollo del software educativo se utilizaron diversos programas de diseño gráfico y de desarrollo Web, como Macromedia freehand, un programa vectorial utilizado para la diagramación, así como para la vectorización del logotipo de la Universidad del Zulia y construcción de botones e iconos. De igual forma, para la diagramación fue utilizado Adobe PhotoShop para el tratamiento y optimización de las imágenes utilizadas, así como para la implementación de efectos y colores. Asimismo, en el contenido y animación fue utilizado Adobe Flash. Se aplicó programación, música y comportamiento al software educativo mediante un lenguaje denominado Action Script; además fueron incluidos los hipervínculos. Igualmente fue usado el Adobe Dreamweaver que es un programa de cuarta generación que permite escribir el lenguaje e integrar todos los elementos y objetos a la página, entre los lenguajes utilizados el principal fue el HTML (Hyper Text Makeup Language), que es el lenguaje de formato de documentos para hipertexto. 


\section{5) La estructura lógica y organización interna del software educativo}

El sistema de navegación del software educativo incluye los aspectos algorítmicos y estructurales que reflejan la estructura del programa, y se concretan en diversos gráficos y diagramas:

Diagrama general del programa (mapa de navegación). Reproduce la estructura básica de su algoritmo. Se representa en forma de diagrama de flujo, y va acompañado de una breve descripción de los módulos globales que lo integran, que son:

- Módulos de presentación y de gestión de menús que comprenden las pantallas de presentación y despedida del programa y las pantallas de gestión de los menús principales.

- Módulos de actividades interactivas que contienen las diferentes actividades educativas que el programa puede presentar a los alumnos.

- Módulos de ayuda que gestionan las ayudas a los alumnos. Aquí se determinaron las formas de acceso a estas ayudas, que son: ayudas sobre el funcionamiento del programa y ayudas didácticas sobre los contenidos.

- Módulos de evaluación que gestionan el almacenamiento de información sobre las actuaciones de los alumnos y la posterior presentación de informes, aquí se determina las informaciones que son relevantes y la forma cómo se accede a ellas y cómo se presentan.

- Módulos auxiliares como gestión de posibles modificaciones de parámetros, utilidades para los alumnos (fotos, links, etc.)

- Organización de los menús que se organizó según un entorno tradicional o según un entorno Windows y en forma de menús desplegables, luego se diseñó el árbol de las opciones que el programa ofrece a los estudiantes.

- Parámetros de configuración del programa que establecieron la posibilidad de que los profesores y los alumnos puedan adaptar algunos aspectos del programa a sus circunstancias, como: conectar o desconectar los efectos sonoros, que no agradan a todos; cambiar el color de algunos elementos de la pantalla; ajustar el tiempo de respuesta para responder o hacer una actividad; fijar el nivel de dificultad de las actividades; elegir el tema mediante programas que pueden gestionar actividades. 
- Los itinerarios pedagógicos (implícitos del programa, explícitos del alumno), representan la secuencia en que se presentaran las actividades y sus posibles bifurcaciones en función de los comportamientos (acciones, errores, etc.) de los estudiantes. En las respuestas se ha dejado el máximo control posible al alumno. El software educativo se ha diseñado considerando las bifurcaciones que permitan seguir diferentes itinerarios pedagógicos a los alumnos y que faciliten: la elección de los temas y de las actividades, la reformulación de los conceptos, el cambio de la secuenciación de los contenidos, el retorno sobre puntos mal comprendidos, la selección del nivel de dificultad, repasar, profundizar y ver ejemplos. La determinación de estos recorridos se puede hacer de dos maneras: a) de manera explícita por libre decisión de los alumnos, que disponen de posibilidades de control directo sobre el programa; y b) De manera implícita en función de las respuestas de los alumnos (tratamiento de los errores y de los aciertos propio de los programas tutoriales).

\section{6) Identificación de vocabulario para satisfacer las necesidades teóricas, ejemplos y ejercicios para mejorar el proceso de aprendizaje y el diseño instruccional que permite la integración y retroalimentación del inglés por medio de ejercicios}

En el diseño del software educativo para la enseñanza de Inglés Técnico, la principal técnica que el equipo de trabajo utilizó fueron "Técnicas para el desarrollo de la creatividad", como la técnica de brainstorming o lluvia de ideas, que facilitó el trabajo del equipo de diseño en la búsqueda de nuevas ideas sobre el qué y el cómo del programa elaborado. Se tomaron en cuenta las posibilidades de los equipos de computación (computadores y periféricos), profundizando en los aspectos técnicos determinantes, y considerando especialmente los aspectos pedagógicos y funcionales.

En la enseñanza de la lectura en Inglés Técnico es imperioso pasar de la lectura unilineal de material impreso a la lectura hipermedia de material digitalizado para extraer eficientemente información requerida. El desarrollo de software educativo con especificaciones particulares para cada grupo hacia dónde va dirigido sigue siendo una exigencia en el uso de las TIC como recurso instruccional. Diseñar un software es pensar, escoger, crear y hacer: esto es un reto a la creatividad, porque al diseñar un software, como se ha dicho, durante su elaboración el equipo de trabajo debe discutir e intercambiar ideas novedosas e interesantes en su formato multimedia; para 
crear un producto adaptado a las características propias del grupo o usuarios a quienes va dirigido para que este sea amigable en su funcionamiento y significativo para el aprendizaje. Para lograr este entramado de creatividad en el diseño del software educativo se aprovechan los nuevos medios como vídeo, audio, inteligencia artificial y realidad virtual, entre otros para cautivar al estudiante y permitirle la construcción del conocimiento.

De esta forma, el uso del software educativo ofrecerá al estudiante asistencia teórica, ejemplos y ejercicios, además de adquirir el feedback pertinente por medio de textos, sonido e hipertextos sin olvidar la estimulación de la animación y las imágenes, lo cual es una forma de presentar material educativo por medio de un programa computarizado que da la oportunidad de una interacción individual, así como también la satisfacción de necesidades y requerimientos.

El software educativo admite relacionar el contenido teórico-programático con la praxis en Inglés Técnico, a través de ejemplos y ayuda teórica adecuada, donde fundamentalmente se hallan ejercicios interactivos con su respectivo feedback para que el estudiante esté consciente de su avance por medio de la concientización de los procedimientos empleados en cada uno de los ejercicios presentados en los programas o software de ejercitación. El software es un gran recurso instruccional ya que le ahorra tiempo al profesor en las fases de ejercitación y retroalimentación, quedando tiempo para atender las necesidades individuales de los alumnos.

El diseño funcional está constituido por el guion del programa, el cual tiene énfasis en los aspectos pedagógicos del proyecto: contenidos, objetivos, estrategias didácticas y tipo de ejercicios. Este diseño ha sido elaborado conjuntamente entre los profesores de Inglés Técnico, expertos en informática educativa y alumnos.

\section{RESULTADOS}

Se ha diseñado un software educativo para la enseñanza de Inglés Técnico para el Aula Multimedia en la Facultad de Ingeniería. Analicemos cada uno de los aspectos instruccionales que contiene el software educativo.

\section{Contenido programático presente en el software educativo}

El contenido programático está elaborado en forma de textos multimedia, de mediana dificultad relacionados con la especialidad de estudio y referen- 
tes con los objetivos programáticos formulados en el programa de estudio vigente. De esta forma, los tópicos de aprendizaje versan sobre los siguientes aspectos: a) Análisis morfológico, claves contextuales y ayudas visuales para deducir significado de palabras nuevas; b) Utilización de diccionarios digitalizados para deducir el significado de palabras desconocidas; c) Análisis de las claves hipermedia para deducir información; d) Localización de información específica; e) Extracción de la idea general del texto; f) Identificación de las funciones retóricas de los textos cientifico-técnicos; g) Identificacion de realizaciones gramaticales como: sinónimos y antónimos, formas verbales, tiempos verbales, adjetivos calificativos, tipos de conectores (de secuencia, de contraste, de ejemplificación, de adición, etc.), referentes contextuales, verbos auxiliares, y h) Identificación de íconos de navegación para leer apropiadamente en ambientes multimedia (Programas de estudio vigentes de Inglés Técnico en Ingeniería, 2008).

Asimismo, estos contenidos programático para ambientes digitalizados han sido diseñados de acuerdo con los intereses y necesidades de los alumnos, de su madurez académica, sus conocimientos previos, su competencia lingüística y su desempeño comunicativo con el propósito de permitir que el aprendizaje del Inglés Técnico sea más útil, actualizado y significativo (Cáceres, 2016).

La organización de los contenidos en los programas tutoriales determina la estructura modular y la secuenciación de las actividades, facilita a los alumnos un aprendizaje significativo y permite diferentes formas de adquisición de la información. En este sentido los contenidos han sido organizados de la siguiente manera (Díaz-Barriga \& Hernández, 2002, González, Marcovecchio, Margarit \& Ureta, 2008, Macías, 2015):

- De los aspectos más fáciles y concretos a los más complejos y abstractos.

- De los elementos conocidos por los alumnos a los que les son desconocidos.

- De los que requieren el uso de habilidades globales a los que implican el uso de habilidades específicas.

- Destacando las relaciones interdisciplinarias para facilitar la transferencia de los aprendizajes. 
- Contemplando niveles de dificultad para facilitar que el alumno escoja el nivel que le interesa y posibilitar que el programa se adapte al nivel de los usuarios.

\section{Actividades interactivas y estrategias de enseñanza y aprendizaje}

Las estrategias didácticas están estrechamente relacionadas con las operaciones mentales que tienen que desarrollar los alumnos durante el aprendizaje de Inglés Técnico (Díaz-Barriga \& Hernández, 2002). A continuación, las estrategias seleccionadas las cuales han sido clasificadas de acuerdo con los siguientes aspectos (González, Marcovecchio, Margarit \& Ureta, 2008, Gavarri, 2016):

Naturaleza de las actividades educativas. Entre este tipo de estrategias están: exposición de información, preguntas, resolución de problemas, búsqueda de información, descubrimiento guiado, descubrimiento experimental. Aquí se han considerado dos tipos de actividades:

- Actividades sencillas, como preguntas y ejercicios que admiten su inmediata ejecución y corrección y suelen responder a un único objetivo formativo. Generalmente son individuales. Por ejemplo: preguntas de elección múltiple, verdadero/falso, respuestas múltiples, asociaciones, unir con líneas, mover, arrastrar y soltar, preguntas con respuesta abierta, entradas numéricas, rellenar blancos.

- Actividades complejas de mayor duración, cuya ejecución requiera la división del trabajo en unas fases secuenciadas. Suelen admitir la organización del trabajo en grupo.

Análisis de las respuestas de los alumnos. Están especificadas por aquellas que prevén el mayor número posible de respuestas y, además, tienen prevista una "salida" para respuestas imprevistas. En el software se han utilizado los siguientes tipos de tratamiento de los errores:

- Según el tipo de refuerzo o de corrección:

- Corrección sin ayuda. Cuando tras detectar el error se da directamente la solución a la pregunta, a veces con comentarios explicativos.

- Corrección con ayuda. Cuando presenta alguna ayuda y permite un nuevo intento al estudiante. La ayuda puede consistir en la 
visualización de diversas respuestas posibles entre las cuales se debe escoger una.

- Según la naturaleza del error. Cada tipo de error establecido requiere un tratamiento contextualizado y diferenciado. Así se distinguen: errores de conocimiento, errores de comprensión, errores de análisis, errores de procedimiento y errores de ejecución.

- Estructura: Aquí se considera el escenario, los elementos relacionados con el contenido y las interrelaciones entre ellos.

\section{Tipos de ejercicios}

Los diferentes tipos de ejercicios utilizados están elaborados considerando la interacción de las actividades y el esfuerzo cognitivo. Estas actividades interactivas promueven en los alumnos actividades intelectuales que favorecen la asimilación significativa de los nuevos conocimientos en sus esquemas internos y que permitan el desarrollo de estrategias de exploración, de aprendizaje a partir de los errores, y de planificación de la propia actividad. Así, los estudiantes pueden construir su propio conocimiento. En este sentido, y para asegurar la significatividad y la transferibilidad de los aprendizajes, las actividades procuran desarrollar en los alumnos formas adecuadas de representación del conocimiento: categorías, secuencias, redes conceptuales y representaciones visuales.

Entre las actividades mentales que los alumnos pueden desarrollar al interactuar con los programas están las siguientes (Cáceres, 2016, González, Marcovecchio, Margarit \& Ureta, 2008, Díaz-Barriga \& Hernández, 2002):

- Ejercitar habilidades psicomotrices. Observar.

- Percibir el espacio y el tiempo y orientarse en ellos.

- Reconocer, identificar, señalar, recordar. Explicar, describir, reconstruir.

- Memorizar (hechos, datos, conceptos, teorías).

- Comparar, discriminar, clasificar. Conceptualizar (conceptos concretos y abstractos).

- Manipular conceptos.

- Relacionar, ordenar. 
- Interpretar, representar, traducir.

- Inferir, prever.

- Buscar selectivamente información.

- Analizar (pensamiento analítico).

- Elaborar hipótesis, deducir.

- Inducir, generalizar.

- Razonar lógicamente (and, or, not). Estructurar.

- Analizar la información críticamente. Evaluar.

- Experimentar (ensayo y error). Construir, crear (expresión creativa, pensamiento divergente.

- Transformar, imaginar (asociaciones, cambios de entorno).

- Expresar, comunicar, exponer estructuradamente.

- Negociar, discutir, decidir.

- Resolver problemas que implican la comprensión de nuevas situaciones.

- Sintetizar, globalizar, resumir.

\section{DISCUSIÓN DE LOS RESULTADOS}

El análisis de los resultados obtenidos para el diseño del software se propone de una manera generalizada, tomando el software como una unidad, como una integralidad de análisis. Esto significa que para su análisis se engloban e interrelacionan todos los elementos que lo constituyen para describirlo en su funcionamiento como recurso instruccional. Desde este punto de vista los resultados obtenidos están en estrecha relación con los elementos didácticos y pedagógicos donde se concibe el software educativo como un medio instruccional para la enseñanza del inglés en ambientes digitalizados. Así, el análisis de los resultados contempla un entretejido de los resultados relativos al contenido programático, las actividades interactivas y estrategias de enseñanza y aprendizaje, y los tipos de ejercicios presentes en el software. 
Los resultados determinan que el diseño del software permite el acceso al contenido programático en formato multimedia donde se consideran el texto, el sonido, el hipertexto, la animación y las imágenes, los cuales satisfacen los requerimientos de teoría y ejercicios que actualizan el proceso de enseñanza del Inglés Técnico mediante la integración de las tecnologías multimedia.

Por otra parte, el software educativo presenta modelos de representación del conocimiento en consonancia con los procesos cognitivos que desarrollan los alumnos durante la lectura. En Inglés Técnico se recomienda el uso de este tipo de software ejercitador que refuerza el conocimiento, además de complementar y servir de apoyo como recurso instruccional en el proceso de aprendizaje del Inglés Técnico.

El software presenta programas que muestran a través de sus actividades unos contenidos que facilitan una información estructuradora de la realidad, al igual que todos los medios didácticos, estos materiales representan la realidad y la ordenan. El software educativo ejercitador orienta y regula el aprendizaje de los estudiantes ya que, explícita o implícitamente, promueve determinadas actuaciones de los mismos guiadas a facilitar el logro de unos objetivos educativos específicos. Además, condiciona el tipo de aprendizaje que se realiza, pues orienta a un tratamiento global de la información del contenido (propio de los medios audiovisuales) o a un tratamiento secuencial (propio de los textos escritos). Asimismo, actúa en general como mediador en la construcción del conocimiento y el metaconocimiento durante la lectura de (hiper) textos. Es el software el que realiza de manera más explícita esta función instructiva del contenido a ser aprendido, ya que dirige las actividades de los estudiantes en función de sus respuestas y progresos.

\section{CONCLUSIONES}

Este software educativo ejercitador está dirigido a adecuar la enseñanza de Inglés Técnico en la Facultad de Ingeniería de la Universidad del Zulia, con la finalidad de que los estudiantes adquieran destrezas de lectura en lenguaje multimedia para interpretar textos científicos escritos en inglés y extraer de ellos la información requerida.

En esta investigación sobre el diseño de un software educativo se especifican los diferentes aspectos que configuran su diseño; como son: el enfoque teórico que le da sustento, el objetivo a lograr, los requerimientos de hardware y software utilizados en su elaboración; así como las destrezas de 
lectura a desarrollar, las estrategias utilizadas para desarrollar la comprensión lectora y el tipo de tópicos de lectura.

Muchas son las posiciones sicolingüísticas y las opiniones provenientes de la Lingüística Aplicada a la enseñanza de Inglés Técnico en el área de la ciencia y la tecnología, por lo tanto, este software educativo ha sido diseñado considerando las últimas teorías sobre la enseñanza de esta asignatura, así como la opinión de otros profesores de Inglés Técnico de la Universidad de Zulia sobre este punto.

La finalidad de este software es, por lo tanto, dirigir conocimientos y habilidades de la lengua (competencia) para resolver problemas de comunicación y problemas de aprendizaje por medio de una gran variedad de actividades en el salón de clases. Del mismo modo, el software está orientado al proceso de aprendizaje y muestra los procedimientos a seguir para la adquisición de la lengua y los mecanismos para aprender cómo utilizar la lengua para aprender. Es decir, proveer las bases para el aprendizaje de la lengua y cómo utilizarla con propósitos comunicativos prácticos.

En el diseño del software el aspecto más importante ha sido el correlacionar las necesidades del estudiante, con los objetivos, el contenido y su implementación en el salón de clase. Así pues, la contribución del estudiante es decisiva en este tipo de software y se caracteriza por la participación activa y constante en el trabajo realizado en clase. Asimismo, el software está diseñado para facilitar la participación del estudiante en las diversas actividades, las cuales generan constantes oportunidades para el aprendizaje de la lengua, y al mismo tiempo concientizan al estudiante de sus capacidades durante el uso práctico de la misma durante la ejercitación, lo cual los motiva a participar en el proceso de enseñanza-aprendizaje, y esto es un factor/meta fundamental en el aprendizaje de Inglés Técnico.

De esta forma, el software educativo contribuye a ser un medio adecuado en la transmisión de la información y del conocimiento en Inglés Técnico, y promueve aspectos inherentes a una enseñanza constructivista como: un aprendizaje controlado en el procesamiento de la información durante los procesos cognitivos promovidos y desarrollados durante la clase; la interactividad entre alumno-computador-software; y la presencia de estrategias y actividades de aprendizaje apropiadas. Así pues, estos aspectos inherentes a la teoría pedagógica del constructivismo y el e-learning presentes en el diseño del software educativo, están diseñadas para contribuir con un aprendizaje significativo, contextualizado, situado y auténtico en el estudiante-aprendiz. 


\section{REFERENCIAS BIBLIOGRÁFICAS}

Bajarlía G. \& Speigel A. (1997). Docentes us@ndo Internet. Buenos Aires, Argentina: Ediciones Novedades Educativas.

Barajas, M. (2003). La tecnología educativa en la enseñanza superior. Entornos virtuales de aprendizaje. Madrid, España: McGraw-Hill/Interamericana de España.

Batista, J. \& Finol, A. (2005). Perspectivas teóricas para la enseñanza de Inglés Técnico en un aula multimedia. Omnia 77(3), 126-146. Recuperado de https://www.redalyc.org/articulo.oa?id=737/73711306

Cabero, J. (2007). Nuevas tecnologías aplicadas a la educación. Madrid, España: McGraw Hill.

Cáceres, S. E. (2016). Diseño de una propuesta tecnológica para la enseñanza y difusión de la Capacitación en Inglés a los estudiantes libres. (Tesis de Especialización en Docencia Universitaria). Universidad de La Plata. Argentina.

Clemente, L., Lara, L. \& Serrano C. (2000). Tecnologías de la Información y Comunicación (TIC) en Venezuela: diagnóstico, problemas y propuestas en relación al grado de preparación de Venezuela para el mundo en red. Proyecto Andino de Competitividad. Venezuela Competitiva.

Consejo Universitario de LUZ (2007). Competencias Generales para los Currículos de la Universidad del Zulia. Maracaibo, Venezuela: Universidad de Zulia.

Consejo Universitario de LUZ (2006). Acuerdo No. 535. Maracaibo, Venezuela: Ediciones del Vicerrectorado Académico de la Universidad del Zulia.

Crook, CH. (1998). Ordenadores y aprendizaje colaborativo. España: Ediciones Morata.

Díaz-Barriga, F. \& Hernández, G. (2002). Estrategias docentes para un aprendizaje significativo una interpretación constructivista. México: McGraw-Hill.

Facultad de Ingeniería de la Universidad del Zulia (2008). Programas de estudios de Inglés Técnico. Venezuela: Universidad de Zulia. 
Fernández-Pampillón, A. (2009). Las plataformas e-learning para la enseñanza y el aprendizaje universitario en Internet. Las plataformas de aprendizaje. Del mito a la realidad. Biblioteca Nueva, Madrid, 45-73. Recuperado de: https://eprints.ucm.es/10682/

Gallego-Badillo, R. (1998). Discurso constructivista sobre las tecnologías. Una mirada epistemológica. Bogotá, Colombia: Colección Mesa Redonda.

Galvis, A. (2000). Ingeniería del Software Educativo. Bogotá, Colombia: Ediciones Uniandes.

García, E., Vite, O., Navarrate, M., García, M., y Torres, V. (2016). Metodología para el desarrollo de software multimedia educativo MEDESME. Revista de Investigación Educativa, 23, 216-226. Recuperado de http://www. redalyc.org/articulo.oa?id $=283146484011$

Gavarri, S.L. (2016). El aprendizaje de lenguas extranjeras mediado por las TIC: Aprender Inglés con Duolingo. El Toldo de Astier 7(12). 56-65. Recuperado de http://www.memoria.fahce.unlp.edu.ar/art_revistas/pr.7199/ pr.7199.pdf

González, M., Marcovecchio, M., Margarit, V., \& Ureta, L. (2008). Tipología de Estrategias de Aprendizaje para la Comprensión Lectora en Inglés en la Modalidad EaD. RED. Revista de Educación a Distancia, (20), 4. Recuperado de: http://www.um.es/ead/red/20

Macías Mendoza, F. (2015). Software educativo para potenciar la competencia comunicativa en Inglés en la Universidad. Dominio de las Ciencias, 7(7), 85-95. Recuperado de http: //dominiodelasciencias.com/ojs/index. php/es/index. Manta, Ecuador

Marquès, P. (2000). Criterios para la selección de software educativo Quaderns Digitals., 24. Recuperado de http://www.quadernsdigitals.net/ articuloquaderns.asp?/dArticle=3560

Marquès, P. (2003). Software educativo multimedia: tipologías. Departamento de Pedagogía Aplicada, Facultad de Educación, UAB. Recuperado de http://peremarques.net/tipologi.htm

Murcia, E., Arias, J. L. \& Osorio, S.M. (2016). Software educativo para el buen uso de las TIC. Entre Ciencia e Ingeniería, 19, 114-125. Recuperado de http://www.researchgate.net/publication/330485592-software-educativo-para-el-buen-usode-las-TIC 
Navarro, M.M., Iglesias, M.P. \& Torres, P.R. (2006). Las competencias profesionales demandadas por las empresas: el caso de los ingenieros. Universidad de Zaragoza. Revista de Educación 347, 643-661. Recuperado de http://www.researchgate.net/profile/Mercedes_Marzo/publication/28132776

Prado, E. (2005). Herramientas Digitales y lenguaje multimedia: retos a la creación. Recuperado de: https://poligrafiabinaria.blogia. com/2005/040803-herramientas-digitales-y-lenguaje-multimedia-retos-a-la-creaci-n.php

Rodríguez, M. \& Planchuelo, D. (2004). Educación, Biblioteca y TIC en la sociedad de la información: reto y compromiso. Boletín de la ANABAD, 54(1-2) 339 - 362. Recuperado de https://dialnet-EducaciónBibliotecaYTICEEEnlasociedaddelainformación-1198718pdf

Romero, R. (2007). Bibliotecas virtuales y alfabetización en Educación. Apertura. Revista de innovación educativa, 17. Recuperado de http://www. udgvirtual.udg.mx/apertura/index.php/apertura/article/view/1220

Salinas, J. (1996). Multimedia en los procesos de enseñanza - aprendizaje: Elementos de discusión. Ponencia en el Encuentro de Computación Educativa. Santiago, Chile.

Sánchez, J. (1999). Construyendo y Aprendiendo con el Computador. Centro Zonal Universidad de Chile. Proyecto Enlaces. Recuperado de http:// www2.udec.cl/avirtual/lap/docts/herramientas.pdf

Silva, E. \& Ávila, F. (2000). Constructivismo. Aplicaciones en Educación (2a Ed.). Maracaibo, Venezuela: Ediciones Astro Data S.A.

Vaughan, T. (2005). Multimedia: making it work. España: McGraw-Hill.

Vicerrectorado Académico de la Universidad del Zulia-LUZ. (2008). Competencias generales de la Universidad del Zulia. Comisión Central de Currículo. Recuperado de http:// www.viceacademico.luz.edu.ve

Wankat, P. \& Oreovicz, F. (1993). Teachning Engineering. Purdue, Estados Unidos: McGrawHill. 